\title{
RESEARCH
}

Open Access

\section{The profile of chiropractors managing patients with low back-related leg pain: analyses of 1907 chiropractors from the ACORN practice-based research network}

Matthew Fernandez ${ }^{1,2^{*}}$ (D) Craig Moore ${ }^{2,3}$, Wenbo Peng ${ }^{3}$, Katie de Luca ${ }^{1,2}$, Katherine A. Pohlman ${ }^{2,4}$, Michael Swain ${ }^{1,2}$ and Jon Adams ${ }^{3}$

\begin{abstract}
Background: Approximately $60 \%$ of people with low back pain also have associated leg pain symptoms. Guidelines for low back pain recommend non-pharmacological approaches, including spinal manipulation - a therapy provided by chiropractors. However, limited empirical data has examined the characteristics of chiropractors managing patients with low back-related leg pain (LBRLP). Our objective is to describe the prevalence, profile and practice characteristics of Australian chiropractors who often treat LBRLP, compared to those who do not often treat LBRLP.
\end{abstract}

Methods: This is a cross-sectional analysis of a nationally representative sample from the Australian Chiropractic Research Network (ACORN). This study investigated the demographic and practice characteristics as well as clinical management of chiropractors who 'often' treated patients with LBRLP compared to those who treated LBRLP 'never/ rarely/sometimes'. Multiple logistic regression models identified independent factors associated with chiropractors who 'often' treated patients with LBRLP.

Results: A total of 1907 chiropractors reported treating patients experiencing LBRLP, with 80.9\% of them 'often' treating LBRLP. Chiropractors who 'often' treated LBRLP were more likely to manage patients with multi-site pain including axial low back pain $(O R=21.1)$, referred/radicular neck pain $(O R=10.8)$ and referred/radicular thoracic pain $(\mathrm{OR}=3.1)$. While no specific management strategies were identified, chiropractors who 'often' treated LBRLP were more likely to discuss medication $(\mathrm{OR}=1.8)$, manage migraine $(\mathrm{OR}=1.7)$ and degenerative spine conditions $(\mathrm{OR}=1.5)$, and treat women during pregnancy $(\mathrm{OR}=1.6)$ and people with work-related injuries $(\mathrm{OR}=1.5)$, compared to those not treating LBRLP frequently.

Conclusions: Australian chiropractors frequently manage LBRLP, although the nature of specific management approaches for this condition remains unclear. Further research on the management of LBRLP can better inform policy makers and educators interested in upskilling chiropractors to deliver safe and effective treatment of LBRLP.

Keywords: Low back pain, Leg pain, Referred, Radicular, Chiropractic, Chiropractor, Practice-based research network

\footnotetext{
* Correspondence: matthew.fernandez@mq.edu.au

'Department of Chiropractic, Faculty of Science and Engineering, Macquarie

University, Level 3, Room 369, 17 Wally's Walk, Sydney, NSW, Australia

${ }^{2}$ Chiropractic Academy for Research Leadership (CARL), Sydney, Australia

Full list of author information is available at the end of the article
}

(c) The Author(s). 2019 Open Access This article is distributed under the terms of the Creative Commons Attribution 4.0 International License (http://creativecommons.org/licenses/by/4.0/), which permits unrestricted use, distribution, and reproduction in any medium, provided you give appropriate credit to the original author(s) and the source, provide a link to the Creative Commons license, and indicate if changes were made. The Creative Commons Public Domain Dedication waiver (http://creativecommons.org/publicdomain/zero/1.0/) applies to the data made available in this article, unless otherwise stated. 


\section{Background}

Approximately $60 \%$ of people who present to primary care with low back pain, also report leg pain due to dysfunctional musculoskeletal or neural structures [1]. However, distinguishing between referred and radicular pain is a clinical challenge [2]. Leg pain caused by ligament, joint or disc structures of the low back is generally classified as referred pain while radicular pain is associated with nerve root compression, largely caused by a herniated intervertebral lumbar disc [3]. There is substantial variation in the prevalence of radicular low back pain, with estimates ranging from 1.6 to 43\% [4]. These variations likely reflect the numerous criteria, definition and assessment methods relating to referred and radicular symptoms in the peer-reviewed literature [5]. For consistency we here employ the terms "referred" and "radicular" to signify low back-related leg pain (LBRLP).

There is a lack of long-term positive effects for the management of LBRLP with respect to prescription medication [6, 7], epidural corticosteroid injections [8] and surgery [9]. While non-pharmacological treatments are preferred, high-quality evidence for the effectiveness of these therapies is scarce. For instance, traction as a single treatment or in combination with physiotherapy, has little to no effect on LBRLP [10]. Exercise is an effective modality compared to usual care [11], and evidence generally supports spinal manipulation compared to sham, no treatment, passive modalities, education and exercise in the management of LBRLP [12]. A more recent high-quality, multimodal randomized controlled trial, which included spinal manipulation together with home exercise and advice as the experimental group, was superior for LBRLP in the short-term, compared to exercise and advice alone in the control group [13].

In Australia chiropractors are a common health provider for those with low back pain [14, 15]. In addition to spinal manipulation [16, 17], chiropractors adopt a multimodal approach, incorporating a number of conservative therapies like soft tissue treatments and exercise prescription $[18,19]$, when managing low back pain [20]. Despite these treatment approaches, there is at present, limited information on the clinical characteristics of chiropractors that frequently manage LBRLP. In response, this study aimed to investigate: 1) the proportion of Australian chiropractors who regularly treat patients who present with lumbar pain and associated referred or radicular symptoms; and 2) the practitioner, clinical practice and clinical management characteristics factors associated with those chiropractors who frequently manage patients who present with lumbar pain and associated referred or radicular symptoms.

\section{Methods}

\section{Study design and setting}

Details of the Australian Chiropractic Research Network (ACORN) project recruitment and participating sample have been outlined elsewhere [21, 22]. Briefly, ACORN a national practice-based research network (PBRN), recruited registered Australian chiropractors for a national-wide cross-sectional survey, between March and July 2015. All 4684 chiropractors registered in Australia at the time of recruitment were invited to participate and received an invitation pack (information sheet, consent form and a 21-item practitioner questionnaire) by post or email. Chiropractors were invited to complete the practitioner questionnaire in either hard copy or online (SurveyGizmo ${ }^{\mathrm{Tm}}$ ). The ACORN survey attracted a completion (response) rate of $43 \%(n=2005)$. The ACORN participants constitute a representative sample of the wider Australian chiropractic population in terms of age, gender, and practice location when compared to national registration records at the time of recruitment [23]. Ethics approval of the ACORN project was obtained from the Human Research Ethics Committee of the University of Technology Sydney (\#2014000027).

\section{Variables and measurements}

The practitioner survey instrument collected information in an attempt to describe chiropractic practice in three key areas. The first was Australian practitioner characteristics comprising of: age, gender, professional qualifications and years in private practice. The second area was clinical practice characteristics, including: average patient care hours, average number of weekly patient visits, practice location, types of health professionals working in the chiropractor's practice location, professional referral relationships and use of diagnostic imaging. The third area was clinical management, divided into four sub-sections and based on a four-point frequency scale ('never', 'rarely', 'sometimes' and 'often') and included: frequency with which the chiropractors discuss listed aspects of health promotion in their care plans; frequency with which the chiropractors treat patients presenting with a range of conditions; frequency with which chiropractors treat certain patient subgroups as listed; and the frequency with which the chiropractors utilise certain treatment techniques/musculoskeletal interventions.

Only participants who completed the clinical management question with regards to the frequency of treating referred/radicular low back pain within the ACORN practitioner questionnaire were included in this study. The ACORN study therefore represents general chiropractic practice (and not behaviours specific to the management of LBRLP). The response options to the people with referred/radicular low back pain (i.e., LBRLP) 
include 'never,' 'rarely,' 'sometimes' and 'often', which were merged into two categories 'never/rarely/sometimes' and 'often' for analyses and interpretation.

\section{Statistical methods}

Practitioner characteristics, clinical practice characteristics and clinical management were compared between chiropractors 'never/rarely/sometimes' treating LBRLP and those 'often' treating LBRLP. Statistical analyses were conducted by the software Stata 13.1. Bivariate analyses were performed via parametric tests and nonparametric tests according to the normality of each variable. A backward stepwise logistic regression was used to identify the most important predictors of chiropractors who are 'often' treating LBRLP compared to those not 'often' treating LBRLP. All variables associated with the LBRLP treatment through bivariate analyses at a $p$-value of $\leq 0.25$ were entered into the regression model [24] and variables were removed from the model if their corresponding coefficient had a p-value $>0.05$. Odds ratios (OR) of the identified predictors were reported with 95\% confidence intervals (95\% CI), based on robust standard error estimators.

\section{Results}

A total of 1907 (95.1\%) ACORN participants included in this present study indicated that they treated patients presenting with LBRLP, and $80.9 \%(n=1543)$ of these participants reported 'often' treating LBRLP. Table 1 shows the comparisons regarding chiropractic practitioner

Table 1 Chiropractors' characteristics regarding the frequency of treating patients with low back-related leg pain

\begin{tabular}{llll}
\hline Characteristics & $\begin{array}{l}\text { Never/ } \\
\text { rarely/ } \\
\text { sometimes } \\
(n=364)\end{array}$ & $\begin{array}{l}\text { Often }(\mathrm{n}= \\
\text { 1543) }\end{array}$ & $\mathrm{p}$ \\
\hline Gender $n$ (\%) & $221(61.2 \%)$ & $967(62.9 \%)$ & \\
$\quad$ Male & $140(38.8 \%)$ & $570(37.1 \%)$ & \\
Female & & & 0.691 \\
Qualification $n$ (\%) & $14(3.9 \%)$ & $42(2.7 \%)$ & \\
Diploma & $122(33.8 \%)$ & $542(35.4 \%)$ & \\
Bachelor & $104(28.8 \%)$ & $456(29.8 \%)$ & \\
Doctor of Chiropractic & $117(32.4 \%)$ & $480(31.4 \%)$ & \\
Masters & $4(1.1 \%)$ & $11(0.7 \%)$ & \\
PhD & Mean (SD) & Mean (SD) & \\
& $42.4(12.1)$ & $42.2(12.1)$ & 0.707 \\
Age (in years) & $15.9(11.5)$ & $15.9(11.3)$ & 0.946 \\
Years in private chiropractic practice & $24.6(10.9)$ & $28.2(16.6)$ & $<0.001$ \\
Patient care hours/week & $73.4(54.1)$ & $90.8(57.7)$ & $<0.001$ \\
\hline Patient visits/week & & &
\end{tabular}

$S D$ standard deviation, $P$ p-value characteristics between those who 'often' treat LBRLP and those who did not often treat LBRLP. There was no statistically significant difference between those 'often' and not often treating LBRLP regarding age, gender, qualifications and years in practice. The average age of chiropractors who often treated LBRLP was 42.2 (SD: 12.1) with $62.9 \%$ being male and an average of 15.9 (SD: 11.3) years in private chiropractic practice. The highest level of chiropractic professional qualification for the overall ACORN study sample was most often Bachelor degree (34.6\%) and Master's degree $(32.7 \%)$ while only $0.9 \%$ of the participated chiropractors have obtained PhD. Similarly, Bachelor degree $(35.4 \%)$ and Master's degree (31.4\%) were also the most common highest qualifications for chiropractors 'often' treating LBRLP, followed by a Doctor of Chiropractic (29.8\%), Diploma (2.7\%), and PhD (0.7\%). Chiropractors who 'often' treated LBRLP reported significantly more patient visits per week on average (mean \pm SD: $90.8 \pm 57.7$ ) and significantly more patient care hours per week on average (mean \pm SD: $28.2 \pm 16.6$ ), compared to those not often treating LBRLP.

The chiropractors' practice characteristics regarding the frequency of treating LBRLP are presented in Table 2. Of those chiropractors who 'often' treated LBRLP, 1143 (74.2\%) practiced in only one location and 1093 (75.3\%) practiced in urban areas exclusively, which were not statistically significantly different than those chiropractors not often treating LBRLP. Chiropractors who 'often' treated LBRLP were more likely to work with another chiropractor in their practice location, compared to those who not often treated this condition $(p=0.004)$. In addition, chiropractors who 'often' treated LBRLP were more likely to hold referral relationships with podiatrists $(p<0.001)$, physiotherapists $(p=0.011)$, and/or exercise physiologist $(p=0.039)$ than chiropractors who not often treated LBRLP. Chiropractors 'often' treating LBRLP were significantly more likely to use diagnostic imaging as part of their practice, compared to those who not often treating this condition $(p<0.001)$.

Table 3 reports the clinical management of chiropractors who treated LBRLP. Several statistically significant differences were found between those chiropractors who 'often' treated LBRLP and those who did not often treat LBRLP for several components related to their care/management plans. For instance, chiropractors who 'often' treated LBRLP were more likely to discuss diet and nutrition $(p<0.001)$, cigarette smoking, drugs and alcohol $(p=0.011)$, physical activity and fitness $(\mathrm{p}$ $<0.001)$, occupational health and safety $(\mathrm{p}<0.001)$, pain counselling $(\mathrm{p}<0.001)$, nutritional supplements $(p=$ $0.004)$, and/or medications $(\mathrm{p}<0.001)$ with their patients, compared to those who did not often treat LBRLP. Moreover, chiropractors 'often' treating LBRLP were more likely to treat patients with neck pain (axial 
Table 2 Chiropractors' practice characteristics regarding the frequency of treating patients with low back-related leg pain

\begin{tabular}{|c|c|c|c|}
\hline Characteristic & $\begin{array}{l}\text { Never/ } \\
\text { rarely/ } \\
\text { sometimes } \\
(n=364)\end{array}$ & $\begin{array}{l}\text { Often }(n= \\
1543)\end{array}$ & $\mathrm{p}$ \\
\hline \multicolumn{4}{|l|}{ Practice location $n(\%)$} \\
\hline Urban & $271(79.5 \%)$ & $1093(75.3 \%)$ & 0.102 \\
\hline One location only & $280(77.6 \%)$ & $1143(74.2 \%)$ & 0.188 \\
\hline \multicolumn{4}{|c|}{ Other practitioners in the same practice location $n(\%)$} \\
\hline General practitioner & $25(6.9 \%)$ & $98(6.4 \%)$ & 0.718 \\
\hline Podiatrist & $35(9.6 \%)$ & $146(9.5 \%)$ & 0.928 \\
\hline Medical specialist & $10(2.8 \%)$ & $42(2.7 \%)$ & 0.979 \\
\hline Physiotherapist & $30(8.2 \%)$ & $148(9.6 \%)$ & 0.426 \\
\hline Another chiropractor & $189(51.9 \%)$ & $929(60.2 \%)$ & 0.004 \\
\hline Exercise physiologist & $17(4.7 \%)$ & $108(7.0 \%)$ & 0.106 \\
\hline Psychologist/Counsellor & $51(14.0 \%)$ & $189(12.3 \%)$ & 0.362 \\
\hline Occupational therapist & $7(1.9 \%)$ & $41(2.7 \%)$ & 0.421 \\
\hline \multicolumn{4}{|c|}{ Referral relationships with other practitioners $n(\%)$} \\
\hline General practitioner & $194(53.3 \%)$ & $890(57.7 \%)$ & 0.129 \\
\hline Podiatrist & $115(31.6 \%)$ & $644(41.7 \%)$ & $<0.001$ \\
\hline Medical specialist & $62(17.0 \%)$ & $244(15.8 \%)$ & 0.568 \\
\hline Physiotherapist & $95(26.1 \%)$ & $509(33.0 \%)$ & 0.011 \\
\hline Exercise physiologist & $44(12.1 \%)$ & $254(16.5 \%)$ & 0.039 \\
\hline Psychologist/Counsellor & $55(15.1 \%)$ & $217(14.1 \%)$ & 0.608 \\
\hline Occupational therapist & $33(9.1 \%)$ & $125(8.1 \%)$ & 0.548 \\
\hline Using diagnostic imaging (used often) $n(\%)$ & $112(31.0 \%)$ & $787(51.3 \%)$ & $<0.001$ \\
\hline
\end{tabular}

$P$ p-value

and referred/radicular), thoracic pain (axial and referred/radicular), low back pain (axial), lower limb musculoskeletal disorders, upper limb musculoskeletal disorders, postural disorders, degenerative spine conditions, headache disorders, migraine disorders, spine health maintenance/prevention, and/or non-musculoskeletal disorders, compared to those not often treating LBRLP (all $p \leq 0.005$ ).

As shown in Table 3, chiropractors who 'often' treated LBRLP were more likely to treat people aged over 65 years, pregnant women, athletes or sports people, people with work-related injuries, people with traffic-related injuries, people receiving post-surgical rehabilitation, and/ or people from non-English speaking ethnic group(s) (all $\mathrm{p} \leq 0.005$ ). Regarding management techniques/methods utilised by chiropractors, those who 'often' treated LBRLP more often used drop-piece techniques/Thompson or similar $(p=0.002)$, biomechanical pelvic blocking/SacroOccipital technique $(p=0.017)$, instrument adjusting ( $p=$ 0.043), high-velocity, low-amplitude adjustment/manipulation/mobilisation $(p<0.001)$, flexion distraction $(p=$ $0.004)$, functional neurology $(p=0.040)$, and/or extremity manipulation $(\mathrm{p}<0.001)$. Also, compared to chiropractors who did not often treat LBRLP, those who 'often' treated LBRLP were more likely to employ musculoskeletal interventions including soft tissue therapy, trigger point therapy, massage therapy, stretching $(p=0.008)$, electro-modalities $(p=0.047)$, heat/cryotherapy $(p=0.002)$, orthotics $(p=$ $0.005)$, and/or specific exercise therapy/rehabilitation/injury taping $(p=0.009)$.

The results of the logistic regression analysis is demonstrated in Table 4. Factors independently associated with chiropractors who more 'often' treat patients with LRLBP include: frequently discuss medications as part of the care/management plan (OR: 1.77; 95\% CI: $1.14-$ $2.73)$, frequently treat referred/radicular neck pain (OR: 10.81; 95\% CI: 6.63-17.63), frequently treat referred/radicular thoracic pain (OR: 3.14; 95\% CI: 1.72-5.71), frequently treat axial low back pain (OR: 21.08 ; $95 \% \mathrm{CI}$ : 10.10-44.00), frequently treat degenerative spine conditions (OR: 1.53; 95\% CI: 1.11-2.11), and/or frequently treat migraine disorders (OR: 1.70; 95\% CI: 1.18-2.43). Additionally, chiropractors who 'often' treated LBRLP were more likely to treat pregnant women (OR: 1.58; 95\% CI: 1.08-2.30) and people with work-related injuries (OR: 1.49; 95\% CI: 1.04-2.14). 
Table 3 Chiropractors' clinical management characteristics regarding the frequency of treating patients with low back-related leg pain

\begin{tabular}{|c|c|c|c|}
\hline Characteristic & $\begin{array}{l}\text { Never/ } \\
\text { rarely/ } \\
\text { sometimes } \\
(n=364)\end{array}$ & $\begin{array}{l}\text { Often }(n= \\
1543)\end{array}$ & $\mathrm{p}$ \\
\hline \multicolumn{4}{|l|}{ Management plan (discussed often) $n(\%)$} \\
\hline Diet/Nutrition & $152(42.2 \%)$ & $810(52.6 \%)$ & $<0.001$ \\
\hline Smoking/Drugs/Alcohol & $71(19.7 \%)$ & $401(26.2 \%)$ & 0.011 \\
\hline Physical activity/Fitness & $282(77.9 \%)$ & $1335(87.0 \%)$ & $<0.001$ \\
\hline Occupational health and safety & $116(32.1 \%)$ & $659(43.2 \%)$ & $<0.001$ \\
\hline Pain counselling & $63(17.6 \%)$ & $403(26.6 \%)$ & $<0.001$ \\
\hline $\begin{array}{l}\text { Nutritional supplements (including vitamins, } \\
\text { minerals, herbs) }\end{array}$ & $110(30.6 \%)$ & $597(38.8 \%)$ & 0.004 \\
\hline Medications (including for pain/inflammation) & $44(12.2 \%)$ & $392(25.8 \%)$ & $<0.001$ \\
\hline \multicolumn{4}{|l|}{ Conditions (treated often) $n(\%)$} \\
\hline Neck pain: Axial & $275(75.8 \%)$ & 1509 (97.9\%) & $<0.001$ \\
\hline Neck pain: Referred/Radicular & $35(9.6 \%)$ & $1162(75.3 \%)$ & $<0.001$ \\
\hline Thoracic pain: Axial & $226(62.4 \%)$ & $1382(90.0 \%)$ & $<0.001$ \\
\hline Thoracic pain: Referred/Radicular & $20(5.6 \%)$ & 857 (56.1\%) & $<0.001$ \\
\hline Low back pain: Axial & $273(75.2 \%)$ & $1525(99.2 \%)$ & $<0.001$ \\
\hline Lower limb musculoskeletal disorders & $135(37.3 \%)$ & $1013(65.7 \%)$ & $<0.001$ \\
\hline Upper limb musculoskeletal disorders & $137(37.7 \%)$ & $1051(68.5 \%)$ & $<0.001$ \\
\hline $\begin{array}{l}\text { Postural disorders (including lordosis, thoracic } \\
\text { kyphosis, scoliosis) }\end{array}$ & $147(41.6 \%)$ & $992(65.9 \%)$ & $<0.001$ \\
\hline $\begin{array}{l}\text { Degenerative spine conditions (including } \\
\text { spondylolisthesis) }\end{array}$ & $134(38.1 \%)$ & 1070 (71.1\%) & $<0.001$ \\
\hline Headache disorders & $229(64.9 \%)$ & $1396(92.5 \%)$ & $<0.001$ \\
\hline Migraine disorders & $77(21.8 \%)$ & $910(60.3 \%)$ & $<0.001$ \\
\hline Spine health maintenance/prevention & $200(56.7 \%)$ & $1158(76.9 \%)$ & $<0.001$ \\
\hline Non-musculoskeletal disorders & $57(22.7 \%)$ & $354(31.6 \%)$ & 0.005 \\
\hline \multicolumn{4}{|l|}{ Patient groups (treated often) $n(\%)$} \\
\hline Older people (65 years or over) & $196(54.4 \%)$ & 1197 (78.0\%) & $<0.001$ \\
\hline Aboriginal and Torres Strait Islander people & $4(1.1 \%)$ & $29(1.9 \%)$ & 0.303 \\
\hline Pregnant women & $81(22.5 \%)$ & $613(40.1 \%)$ & $<0.001$ \\
\hline Athletes or sports people & $115(32.1 \%)$ & $819(53.7 \%)$ & $<0.001$ \\
\hline People with work-related injuries & $74(21.3 \%)$ & $594(39.5 \%)$ & $<0.001$ \\
\hline People with traffic-related injuries & $18(5.1 \%)$ & $235(15.7 \%)$ & $<0.001$ \\
\hline People receiving post-surgical rehabilitation & $11(3.2 \%)$ & $109(7.3 \%)$ & 0.005 \\
\hline Non-English speaking ethnic group(s) & $9(2.7 \%)$ & $108(7.4 \%)$ & 0.002 \\
\hline \multicolumn{4}{|l|}{ Techniques/methods (used often) $n$ (\%) } \\
\hline Drop-piece techniques/Thompson or similar & $167(46.7 \%)$ & $843(55.6 \%)$ & 0.002 \\
\hline $\begin{array}{l}\text { Biomechanical pelvic blocking/ } \\
\text { Sacro-Occipital technique }\end{array}$ & $138(38.3 \%)$ & $684(45.3 \%)$ & 0.017 \\
\hline Instrument adjusting & $170(47.4 \%)$ & $810(53.3 \%)$ & 0.043 \\
\hline Chiropractic BioPhysics & $14(4.1 \%)$ & $64(4.4 \%)$ & 0.766 \\
\hline $\begin{array}{l}\text { High velocity, low amplitude adjustment/ } \\
\text { manipulation/mobilisation }\end{array}$ & $265(73.8 \%)$ & $1283(84.4 \%)$ & $<0.001$ \\
\hline Applied kinesiology & $51(14.4 \%)$ & $246(16.5 \%)$ & 0.343 \\
\hline
\end{tabular}


Table 3 Chiropractors' clinical management characteristics regarding the frequency of treating patients with low back-related leg pain (Continued)

\begin{tabular}{|c|c|c|c|}
\hline Characteristic & $\begin{array}{l}\text { Never/ } \\
\text { rarely/ } \\
\text { sometimes } \\
(n=364)\end{array}$ & $\begin{array}{l}\text { Often }(n= \\
1543)\end{array}$ & $p$ \\
\hline Flexion-distraction & $15(4.2 \%)$ & $132(8.9 \%)$ & 0.004 \\
\hline Functional neurology & $35(10.0 \%)$ & $209(14.2 \%)$ & 0.040 \\
\hline Extremity manipulation & $169(47.1 \%)$ & $939(61.8 \%)$ & $<0.001$ \\
\hline \multicolumn{4}{|l|}{$\begin{array}{l}\text { Musculoskeletal interventions (used } \\
\text { often) } n(\%)\end{array}$} \\
\hline Dry needling or acupuncture & $40(11.2 \%)$ & $219(14.4 \%)$ & 0.110 \\
\hline $\begin{array}{l}\text { Soft tissue therapy, trigger point } \\
\text { therapy, massage therapy, stretching }\end{array}$ & $218(60.4 \%)$ & $1036(67.7 \%)$ & 0.008 \\
\hline $\begin{array}{l}\text { Electro-modalities (TENS, laser, interferential/ } \\
\text { ultrasound therapy) }\end{array}$ & $25(6.9 \%)$ & $158(10.4 \%)$ & 0.047 \\
\hline Heat/Cryotherapy & $40(11.1 \%)$ & $273(18.0 \%)$ & 0.002 \\
\hline Orthotics & $22(6.1 \%)$ & $169(11.2 \%)$ & 0.005 \\
\hline $\begin{array}{l}\text { Specific exercise therapy/rehabilitation/ } \\
\text { injury taping }\end{array}$ & $155(43.2 \%)$ & $770(50.8 \%)$ & 0.009 \\
\hline
\end{tabular}

$P$ p-value

Table 4 Logistic regression analysis identifying predictors for chiropractors who often treat patients with low back-related leg pain as compared to those who do not

\begin{tabular}{|c|c|c|c|}
\hline Factors & Odds Ratio & $95 \% \mathrm{Cl}$ & $P$ \\
\hline Axial low back pain & & & $<0.001$ \\
\hline Never/rarely/sometimes & Reference & 1.00 & \\
\hline Often & 21.08 & $10.10,44.00$ & \\
\hline Referred/radicular neck pain & & & $<0.001$ \\
\hline Never/rarely/sometimes & Reference & 1.00 & \\
\hline Often & 10.81 & $6.63,17.63$ & \\
\hline Referred/radicular thoracic pain & & & $<0.001$ \\
\hline Never/rarely/sometimes & Reference & 1.00 & \\
\hline Often & 3.14 & $1.72,5.71$ & \\
\hline Discussing medications & & & 0.010 \\
\hline Never/rarely/sometimes & Reference & 1.00 & \\
\hline Often & 1.77 & $1.14,2.73$ & \\
\hline Migraine disorders & & & 0.004 \\
\hline Never/rarely/sometimes & Reference & 1.00 & \\
\hline Often & 1.70 & $1.18,2.43$ & \\
\hline Pregnant women & & & 0.017 \\
\hline Never/rarely/sometimes & Reference & 1.00 & \\
\hline Often & 1.58 & $1.08,2.30$ & \\
\hline Degenerative spine conditions & & & 0.010 \\
\hline Never/rarely/sometimes & Reference & 1.00 & \\
\hline Often & 1.53 & $1.11,2.11$ & \\
\hline People with work-related injuries & & & 0.030 \\
\hline Never/rarely/sometimes & Reference & 1.00 & \\
\hline Often & 1.49 & $1.04,2.14$ & \\
\hline
\end{tabular}

\section{Discussion}

Our study identifies several clinical management differences among chiropractors who 'often' treat LBRLP compared to those who do not often treat this condition. One finding is that those chiropractors who 'often' treat LBRLP, are more likely to discuss medication for pain and inflammation with patients. Given the more intense pain and disability associated with LBRLP, compared to non-specific low back pain [25], this finding is not unexpected. Pain medication discussions may also be underpinned by the considerable side effects associated with numerous pharmacological interventions for LBRLP [7], and with uncertainty regarding medication efficacy and tolerability [6], major international clinical guidelines for non-specific low back and leg pain now discourage the use of analgesic medication for this condition [11, 26, 27]. Chiropractors presently do not have medication prescription rights in Australia [28], yet a baseline level of pharmacological understanding, such as medication usage and harmful interactions between different medications or adverse drug reactions [29] is essential knowledge for chiropractors [30], particularly in older people with LBRLP [31]. Importantly, many other factors may influence a chiropractor's decision to discuss medication with patients that are not solely due to LBRLP. For instance, medications such as hypertensive drugs may influence chiropractic care [32], while others such as blood thinners, may pose a risk, for example an increased risk of bleeding and constitute important clinical information for chiropractors to ensure quality and safe patient care [33]. The specific nature of medication discussions of Australian chiropractors regarding LBRLP in 
this study were not examined and requires further examination in future research.

Our study also found that chiropractors who 'often' treat LBRLP are more likely to provide treatment to other spinal pain regions, including referred/radicular neck pain and referred/radicular thoracic pain (in addition to axial low back pain) than those chiropractors who do not often treat LBRLP. This finding may possibly be explained by research indicating that lumbar, thoracic and cervical spine pain are likely part of a general musculoskeletal pain syndrome rather than a distinct, site-specific complaint [34]. LBRLP is reportedly more prevalent and frequent in those who report pain at multiple musculoskeletal sites $[35,36]$. Although the mechanism behind multiple co-occurring pain regions is unknown, low back and neck pain for instance, share many commonalities including similar one year prevalence rates [37, 38], poorer health [35] and increased comorbidity [39]. Chiropractors integrate several manual-based techniques in clinical practice [22], and our analyses suggests multi-region manual therapy may already be carried out by chiropractors managing LBRLP. Nevertheless, musculoskeletal guidelines generally focus on single site-specific complaints, hence a greater understanding of the management of multi-region spinal and coexisting musculoskeletal pain problems is required [40].

Chiropractors who 'often' treat LBRLP as shown in our study, will also often treat people with degenerative spine conditions. This finding was not unexpected, with degenerative spine conditions such as lumbar spinal stenosis (i.e., age-related central and/or lateral lumbar spinal canal narrowing) identified as a common cause of LBRLP and disability in older people [41].

There is a marked reduction in physical and mental quality of life, and a subsequent impact in older adults functional capacity, i.e., walking, due to degenerative LBRLP [42]. As a result, many older people utilize chiropractic services due to degenerative lumbar spinal complaints [43]. For instance, an Australian study found 13\% of patient encounters were those aged 65 years and older [15], while an American study showed approximately $14 \%$ of chiropractic patients are over the age of 65 years, with low back pain the most common musculoskeletal complaint [43]. Despite this utilisation, there is a lack of high-quality evidence for the conservative management of lumbar spinal stenosis [41, 44]. Although a recent clinical trial showed good, short-term pain and functional outcomes [45], there is a greater need for more chiropractic research regarding the long-term effectiveness of optimal LBRLP treatment in people with degenerative spine conditions $[20,46,47]$.

Chiropractors who 'often' treat LBRLP in this present study are more likely to provide treatment to pregnant women when compared to chiropractors not often treating LBRLP. Given the changes in centre of gravity, weight gain and ligamentous laxity throughout the pregnancy, labour, and post-partum periods [48], this finding is plausible. Women frequently seek chiropractic care for pregnancy, with $80 \%$ reporting low back pain or pelvic pain [49] or a combination of both [50]. Further, recent data has identified prevalence rates as high as $22 \%$ in pregnant women who experience LBRLP and seek chiropractic care [51]. Previous systematic reviews also report favourable effects regarding the efficacy of chiropractic treatment for pregnancy-related low back pain $[49,52,53]$. As emerging research indicates that a considerable proportion of pregnant women with LBRLP seek treatment [54], chiropractic appears to represent a substantial care option for this population group.

In this study, the treatment of people with work-related injuries are another factor independently associated with chiropractors 'often' treating LBRLP. This relationship may relate to the increased loading of lumbar spine structures [55], during physically strenuous or demanding workloads (i.e., whole body vibration, frequent bending, twisting and lifting), are known risk factors for both non-specific low back and LBRLP [56-60]. As such, work-related LBRLP complaints are common, placing a substantial economic burden on health-care services [61]. Hence, it is reasonable to expect workplace injury prevention-like strategies taking place within the chiropractic setting, by not only treating injured workers but discussing the modification of physical and psychosocial factors (i.e., patient fear and sense of vulnerability related to injury) to reduce injury risk and cost [62]. Structured exercise is one intervention shown to be protective in managing LBRLP in the short-term [63], while physical activity, i.e., walking and cycling [64], is also protective against work-related LBRLP [65]. While a national-based study found that $85 \%$ of Australian chiropractors report discussing physical activity and/or exercise interventions with patients [22], whether these discussions specifically target work-related injuries and LBRLP remains unclear.

\section{Limitations}

Our study explores personal, practice and clinical characteristics of chiropractors who frequently treat LBRLP, identifying valuable questions for future investigation regarding the chiropractic management of this condition. However, there are limitations to our research that need to be considered. The ACORN practitioner questionnaire was designed to provide high-quality baseline data regarding the chiropractic workforce and not the management of specific clinical chiropractic conditions. Despite the ACORN survey attracting a response rate of $43 \%$, it is one of the largest voluntary workforce samples in both chiropractic and allied health care to date [21]. 
The ACORN survey combined the terms "referred" and "radicular" low back pain to indicate LBRLP, yet most published guidelines on low back pain support the identification of patients with leg pain due to nerve root involvement [66]. There may also be the potential for recall bias, given the self-reported nature of our study.

\section{Conclusion}

Nearly three-quarters of Australian chiropractors reported frequently managing LBRLP, yet the specific nature of both their analyses and management approaches related to LBRLP remains unclear. Further, in-depth research is required with respect to these topics to better inform policy-makers, practitioners, educators and patients regarding the safe and effective treatment of LBRLP by chiropractors amongst the range of health providers available for this condition.

\section{Abbreviations}

ACORN: Australian Chiropractic Research Network; LBRLP: Low back-related leg pain; PBRN: practice-based research network

\section{Acknowledgements}

The ACORN project is funded by the Chiropractors' Association of Australia (CAA) and the authors are grateful their financial support for the ACORN PBRN. The authors also wish to acknowledge and thank the Australian chiropractors who participated in this study. Finally, the authors are solely responsible for the research reported in this paper and the CAA has no influence over the study design or analyses presented in this manuscript.

\section{Funding}

No external funding was provided

\section{Availability of data and materials}

The datasets used and/or analyzed during the current study are available from co-author Jon Adams (UTS) on reasonable request.

\section{Authors' contributions}

MF, CM and JA initiated and designed the study protocol. WP and JA undertook the data analysis and interpretation. All authors were responsible for reviewing and redrafting the final version of the manuscript. All authors read and approved the final manuscript.

\section{Ethics approval and consent to participate}

Ethics approval of the ACORN project was obtained from the Human Research Ethics Committee of the University of Technology Sydney (\#2014000027).

\section{Consent for publication}

Not applicable.

\section{Competing interests}

The authors declare that they have no competing interest.

\section{Publisher's Note}

Springer Nature remains neutral with regard to jurisdictional claims in published maps and institutional affiliations.

\section{Author details}

'Department of Chiropractic, Faculty of Science and Engineering, Macquarie University, Level 3, Room 369, 17 Wally's Walk, Sydney, NSW, Australia. ${ }^{2}$ Chiropractic Academy for Research Leadership (CARL), Sydney, Australia. ${ }^{3}$ Faculty of Health, University of Technology Sydney, Sydney, NSW, Australia. ${ }^{4}$ Research Institute, Parker University, Dallas, Texas, USA.
Received: 12 September 2018 Accepted: 18 February 2019

Published online: 17 April 2019

\section{References}

1. Hill JC, Konstantinou K, Egbewale BE, Dunn KM, Lewis M, van der Windt D. Clinical outcomes among low Back pain consulters with referred leg pain in primary care. Spine. 2011;36(25):2168-75.

2. Stynes S, Konstantinou K, Dunn KM, Lewis M, Hay EM. Reliability among clinicians diagnosing low back-related leg pain. Eur Spine J. 2016;25(9): 2734-40.

3. Koes BW, van Tulder MW, Peul WC. Diagnosis and treatment of sciatica. BMJ. 2007;334(7607):1313-7.

4. Konstantinou K, Dunn KM. Sciatica: review of epidemiological studies and prevalence estimates. Spine. 2008;33(22):2464-72.

5. Lin CWC, Verwoerd AJH, Maher CG, Verhagen AP, Pinto RZ, Luijsterburg PAJ, et al. How is radiating leg pain defined in randomized controlled trials of conservative treatments in primary care? A systematic review. Eur J Pain. 2014;18(4):455-64

6. Pinto RZ, Maher CG, Ferreira ML, Ferreira PH, Hancock M, Oliveira VC, et al. Drugs for relief of pain in patients with sciatica: systematic review and meta-analysis. BMJ. 2012;344:e497.

7. Pinto RZ, Verwoerd AJH, Koes BW. Which pain medications are effective for sciatica (radicular leg pain)? BMJ. 2017;359:j4248.

8. Chou R, Hashimoto R, Friedly J, Fu R, Bougatsos C, Dana T, et al. Epidural corticosteroid injections for radiculopathy and spinal StenosisA systematic review and meta-analysisEpidural corticosteroid injections for radiculopathy and spinal stenosis. Ann Intern Med. 2015;163(5):373-81.

9. Fernandez M, Ferreira ML, Refshauge KM, Hartvigsen J, Silva IRC, Maher CG, et al. Surgery or physical activity in the management of sciatica: a systematic review and meta-analysis. Eur Spine J. 2016;25(11):3495-512.

10. Wegner I, Widyahening IS, van Tulder MW, Blomberg SE, de Vet HC, Brønfort G, et al. Traction for low-back pain with or without sciatica. Cochrane Database Syst Rev; 2013. https://doi.org/10.1002/14651858. CD003010.pub5. [PMID: 23959683].

11. Qaseem A, Wilt TJ, RM ML, Forciea M, for the Clinical Guidelines Committee of the American College of P. Noninvasive treatments for acute, subacute, and chronic low back pain: A clinical practice guideline from the american college of physicians. Ann Intern Med. 2017;166(7):514-30.

12. Leininger B, Bronfort G, Evans R, Reiter T. Spinal manipulation or mobilization for radiculopathy: a systematic review. Phys Med Rehabil Clin N Am. 2011:22(1):105-25.

13. Bronfort G, Hondras MA, Schulz CA, Evans RL, Long CR, Grimm R. Spinal manipulation and home exercise with advice for subacute and chronic back-related leg pain: a trial with adaptive allocation. Ann Intern Med. 2014; 161(6):381-91.

14. Brown BT, Bonello R, Fernandez-Caamano R, Graham PL, Eaton S, Green H. Chiropractic in Australia: a survey of the general public. Chiropractic J Australia. 2013:43(3):85-92.

15. French SD, Charity MJ, Forsdike K, Gunn JM, Polus BI, Walker BF, et al. Chiropractic observation and analysis study (COAST): providing an understanding of current chiropractic practice. Med J Aust. 2013;199(10): 687-91.

16. Shekelle PG, Adams AH, Chassin MR, Hurwitz EL, Brook RH. SPinal manipulation for low-back pain. Ann Intern Med. 1992;117(7):590-8.

17. Bronfort G, Haas M, Evans R, Kawchuk G, Dagenais S. Evidence-informed management of chronic low back pain with spinal manipulation and mobilization. Spine J. 2008;8(1):213-25.

18. Hurwitz EL. Epidemiology: spinal manipulation utilization. J Electromyogr Kinesiol. 2012:22(5):648-54

19. Walker BF, French SD, Grant W, Green S. Combined chiropractic interventions for low-back pain. Cochrane Database Syst Rev. 2010;4(4): CD005427.

20. Clijsters M, Fronzoni F, Jenkins H. Chiropractic treatment approaches for spinal musculoskeletal conditions: a cross-sectional survey. Chiropr Man Therap. 2014;22(1):33.

21. Adams J, Peng W, Steel A, Lauche R, Moore C, Amorin-Woods L, et al. A cross-sectional examination of the profile of chiropractors recruited to the Australian Chiropractic Research Network (ACORN): a sustainable resource for future chiropractic research. BMJ Open. 2017;7(9):e015830.

22. Adams J, Lauche R, Peng W, Steel A, Moore C, Amorin-Woods LG, et al. A workforce survey of Australian chiropractic: the profile and practice features 
of a nationally representative sample of 2,005 chiropractors. BMC Complement Altern Med. 2017;17(1):14.

23. Adams J, Steel A, Moore C, Amorin-Woods L, Sibbritt D. Establishing the ACORN National Practitioner Database: strategies to recruit practitioners to a National Practice-Based Research Network. J Manipulative Physiol Ther. 2016;39(8):594-602.

24. Hosmer David W, Stanley L. Applied logistic regression. 2nd ed. New York: Wiley; 2000

25. Selim AJ, Ren XS, Fincke G, Deyo RA, Rogers N, Miller D. The importance of radiating leg pain in assessing health outcomes among patients with low back pain. Results from the veterans health study. Spine. 1998;23(4):470-4.

26. Stochkendahl MJ, Kjaer P, Hartvigsen J, et al. National clinical guidelines for non-surgical treatment of patients with recent onset low back pain or lumbar radiculopathy. Eur Spine J. 2018;27:60-75

27. Bernstein IA, Malik Q, Carville S, Ward S. Low back pain and sciatica: summary of NICE guidance. BMJ. 2017;356:6748.

28. Emary PC, Houweling TAW, Wangler M, Burnie SJ, Hood KJ, Erwin WM. A commentary on the implications of medication prescription rights for the chiropractic profession. Chiropr Man Ther. 2016;24(1):33.

29. Han B, Compton WM, Blanco C, Crane E, Lee J, Jones CM. Prescription opioid use, misuse, and use disorders in u.s. adults: 2015 national survey on drug use and health. Ann Intern Med. 2017;167(5):293-301.

30. Draper B, Rigoni N. Prescription medication use in a chiropractic training clinic: Cause for vigilance. Complement Ther Clin Pract. 2016;22(Supplement C):59-63.

31. Ferreira ML, McLachlan A. The challenges of treating sciatica pain in older adults. Drugs Aging. 2016;33(11):779-85.

32. Goertz CM, Salsbury SA, Vining RD, Long CR, Pohlman KA, Weeks WB, et al. Effect of spinal manipulation of upper cervical vertebrae on blood pressure: results of a pilot sham-controlled trial. J Manip Physiol Ther. 2016:39(5):369-80.

33. Sullivan G, Lansbury G. Physiotherapists' knowledge of their clients' medications: a survey of practising physiotherapists in New South Wales, Australia. Physiother Theory Pract. 1999;15(3):191-8.

34. Hartvigsen J, Nielsen J, Kyvik KO, Fejer R, Vach W, lachine I, et al. Heritability of spinal pain and consequences of spinal pain: a comprehensive genetic epidemiologic analysis using a population-based sample of 15,328 twins ages 20-71 years. Arthritis Care Res. 2009;61(10):1343-51.

35. Coggon D, Ntani G, Walker-Bone K, Palmer KT, Felli VE, Harari R, et al. Epidemiological differences between localised and non-localised low back pain. Spine. 2017:42(10):740.

36. Carnes D, Parsons S, Ashby D, Breen A, Foster NE, Pincus T, et al. Chronic musculoskeletal pain rarely presents in a single body site: results from a UK population study. Rheumatology (Oxford). 2007;46(7):1168-70.

37. Hoy D, Bain C, Williams G, March L, Brooks P, Blyth F, et al. A systematic review of the global prevalence of low back pain. Arthritis Rheumatism. 2012;64(6):2028-37.

38. Fejer R, Kyvik KO, Hartvigsen J. The prevalence of neck pain in the world population: a systematic critical review of the literature. Eur Spine J. 2006; 15(6):834-48.

39. de Luca KE, Parkinson L, Haldeman S, Byles JE, Blyth F. The relationship between spinal pain and comorbidity: a cross-sectional analysis of 579 community-dwelling, older Australian women. J Manip Physiol Ther. 2017; 40(7):459-66.

40. Babatunde OO, Jordan JL, Van der Windt DA, Hill JC, Foster NE, Protheroe J. Effective treatment options for musculoskeletal pain in primary care: a systematic overview of current evidence. PLoS One. 2017;12(6):e0178621.

41. Kreiner DS, Shaffer WO, Baisden JL, Gilbert TJ, Summers JT, Toton JF, et al. An evidence-based clinical guideline for the diagnosis and treatment of degenerative lumbar spinal stenosis (update). Spine J. 2013;13(7):734-43

42. Hicks GE, Gaines JM, Shardell M, Simonsick EM. Associations of back and leg pain with health status and functional capacity of older adults: findings from the retirement community back pain study. Arthritis Care Res. 2008; 59(9):1306-13.

43. Weigel P, Hockenberry JM, Bentler SE, Obrizan M, Kaskie B, Jones MP, et al, A longitudinal study of chiropractic use among older adults in the United States. Chiropractic Osteopat. 2010;18(1):34.

44. Ammendolia C, Stuber K, de Bruin LK, Furlan AD, Kennedy CA, Rampersaud $Y R$, et al. Nonoperative treatment of lumbar spinal stenosis with neurogenic claudication: a systematic review. Spine. 2012:37(10):E609-E16.
45. Schneider MJ, Ammendolia C, Murphy DR, Glick RM, Hile E, Tudorascu DL, et al. Comparative Clinical Effectiveness of Nonsurgical Treatment Methods in Patients With Lumbar Spinal Stenosis: A Randomized Clinical Trial. JAMA Network Open. 2019;2(1):e186828-e.

46. Gleberzon B, Hawk C, Dougherty P, Schneider MJ, Haas M, Killinger LZ, et al. Response to letter to editor: "best practices for chiropractic Care for Older Adults: a consensus update". J Manip Physiol Ther. 2017;40(7):545.

47. Matsuwaka ST, Liem BC. The role of exercise in treatment of lumbar spinal stenosis symptoms. Curr Phys Med Rehabil Rep. 2018;6(1):36-44.

48. Al-Khodairy A-WT, Bovay P, Gobelet C. Sciatica in the female patient: anatomical considerations, aetiology and review of the literature. Eur Spine J. 2007;16(6):721-31

49. Stuber KJ, Smith DL. Chiropractic treatment of pregnancy-related low Back pain: a systematic review of the evidence. J Manip Physiol Ther. 2008;31(6): $447-54$

50. Weis CA, Barrett J, Tavares P, Draper C, Ngo K, Leung J, et al. Prevalence of low Back pain, pelvic girdle pain, and combination pain in a pregnant Ontario population. J Obstet Gynaecol Can. 2018;40(8):1038-43.

51. Steel A, Adams J, Sibbritt D, Broom A, Gallois C, Frawley J. Utilisation of complementary and alternative medicine (CAM) practitioners within maternity care provision: results from a nationally representative cohort study of 1,835 pregnant women. BMC Pregnancy Childbirth. 2012:12(1):146.

52. Khorsan R, Hawk C, Lisi AJ, Kizhakkeveettil A. Manipulative therapy for pregnancy and related conditions: a systematic review. Obstet Gynecol Surv. 2009;64(6):416-27.

53. Hall H, Cramer H, Sundberg T, Ward L, Adams J, Moore C, et al. The effectiveness of complementary manual therapies for pregnancy-related back and pelvic pain: A systematic review with meta-analysis. Med. 2016; 95(38):e4723.

54. Hall H, Lauche R, Adams J, Steel A, Broom A, Sibbritt D. Healthcare utilisation of pregnant women who experience sciatica, leg cramps and/or varicose veins: a cross-sectional survey of 1835 pregnant women. Women Birth. 2016:29(1):35-40.

55. Huang W, Han Z, Liu J, Yu L, Yu X. Risk factors for recurrent lumbar disc herniation: a systematic review and meta-analysis. Medicine. 2016;95(2): e2378.

56. Euro U, Knekt P, Rissanen H, Aromaa A, Karppinen J, Heliövaara M. Risk factors for sciatica leading to hospitalization. Eur Spine J; 2017. https://doi. org/10.1007/s00586-017-5182-8

57. Kaila-Kangas L, Leino-Arjas P, Karppinen J, Viikari-Juntura E, Nykyri E, Heliövaara M. History of physical work exposures and clinically diagnosed sciatica among working and nonworking Finns aged 30 to 64. Spine. 2009; 34(9):964-9

58. Sørensen IG, Jacobsen P, Gyntelberg F, Suadicani P. Occupational and other predictors of herniated lumbar disc disease-a 33-year follow-up in the Copenhagen male study. Spine. 2011:36(19):1541-6.

59. Miranda H, Viikari-Juntura E, Martikainen R, Takala E-P, Riihimäki H. Individual factors, occupational loading, and physical exercise as predictors of sciatic pain. Spine. 2002;27(10):1102-8

60. Kuijer PPF, Verbeek JH, Seidler A, Ellegast R, Hulshof CT, Frings-Dresen MH, et al. Work-relatedness of lumbosacral radiculopathy syndrome: Review and dose-response meta-analysis. Neurology. 2018. https://doi.org/10.1212/01. wnl. 000054432226939.09

61. Australian Institute of Health and Welfare 2016. Impacts of chronic back problems. Bulletin 137. Cat. No. AUS 204. Canberra: AlHW: 2016.

62. Côté P, Clarke J, Deguire S, Frank JW, Yassi A. Chiropractors and return-towork: the experiences of three Canadian focus groups. J Manip Physiol Ther. 2001;24(5):309-16

63. Fernandez M, Hartvigsen J, Ferreira ML, Refshauge KM, Machado AF, Lemes ÍR, et al. Advice to stay active or structured exercise in the Management of Sciatica: a systematic review and meta-analysis. Spine. 2015;40(18):1457-66.

64. Shiri R, Euro U, Heliövaara M, Hirvensalo M, Husgafvel-Pursiainen $\mathrm{K}$, Karppinen J, et al. Lifestyle risk factors increase the risk of hospitalization for sciatica: findings of four prospective cohort studies. Am J Med. 2017;130(12): 1408-1414.e6.

65. Shiri R, Falah-Hassani K, Viikari-Juntura E, Coggon D. Leisure-time physical activity and sciatica: a systematic review and meta-analysis. Eur J Pain. 2016; 20(10):1563-72.

66. Haswell K, Gilmour J, Moore B. Clinical decision rules for identification of low Back pain patients with neurologic involvement in primary care. Spine. 2008;33(1):68-73. 